\title{
Association between asthma and family size between 1977 and 1994
}

\author{
R J Rona, J M Hughes, S Chinn
}

\begin{abstract}
Study objectives-Several recent reports show a negative association between asthma and family size or birth order, but this association was not detected in data collected between 10 and 30 years ago. This study compared the association between sibship size and asthma in three surveys using the same methodology in $1977,1985 / 86$, and 1993/94.

Design-Cross sectional comparison of the $1977,1985 / 86$, and $1993 / 94$ surveys. Settings-Study areas in England and Scotland

Participants-Parents of children between 5 to 11 years in England and Scotland were asked about asthma and bronchitis attacks in the last 12 months, and wheeze in their child. Approximately 9000 children participated in each of the surveys.

Results-The overall association between asthma, defined as asthma attacks or wheeze, and total number of siblings was not significant $(p=0.22)$, but an only child had a higher prevalence of asthma than children with siblings (OR 0.87 95\% CI 0.76 to 0.98 ). The interaction between year of survey and sibship size on asthma was not significant $(p=0.36)$. There was no association between asthma and birth order. A significant interaction between social class and year of survey on asthma was detected $(p=0.004)$. In the $1993 / 94$ survey children whose fathers had a semi or unskilled manual occupation had a higher prevalence of asthma (16\%) than children whose fathers belonged to other social classes $(13 \%)$.

Conclusions-This study provides only marginal support for a change over time of the association between sibship size and asthma. Based on recent reports the nature of the exposure agent that may explain the association remains controversial. This study suggests a disproportionate increase of asthma in lower social classes. (F Epidemiol Community Health 1999;53:15-19)
\end{abstract}

A negative association has been reported between number of siblings or birth order and the prevalence of hay fever, ${ }^{1-3}$ eczema, ${ }^{12}$ allergic sensitisation, ${ }^{3-8}$ and asthma symptoms. ${ }^{9-11}$ Based on this evidence an aetiological hypothesis has been developed that attributes the emergence of atopic conditions to a protective effect of infection at an early age. Repeated viral infection would be more likely in a young child with many older siblings and this will decrease the chance of a child developing an atopic condition. ${ }^{12}$
There are some indications that these repeated infections may inhibit the proliferation of Th-2 clones and increase the proliferation of Th-1 clones. Th- 2 cells are associated with allergic conditions. ${ }^{13}$ The hypothesis has at least two weak points. Firstly, the relation between family size with allergic conditions is more consistent than that with birth order. ${ }^{511}$ This may be to a certain extent because of the analytical difficulty of distinguishing birth order from family size. Secondly, it is puzzling that studies based on data collected long ago showed no association between family size and asthma or wheeze ${ }^{14-17}$ while more recent data tend to show an association with both. ${ }^{7911}$ In the study of Davis and Bulpitt the lack of association was not restricted to asthma, but observed also for atopy. ${ }^{14}$ This indicates that either the identification of cases, the nature of the disease or a sudden environmental change occurred over time.

In the National Study of Health and Growth (NSHG) information on respiratory illness in 5 to 11 year olds was collected over the period 1972 to 1994 . The 1990 and 1991 surveys were used for an analysis of asthma and sibship size or birth order and a very strong association was reported. ${ }^{11}$ This study reports on the level of association between these variables in three surveys, one carried out in 1977, another in 1985 and 1986, and the last in 1993 and 1994. The aim was to assess whether the association between sibship size and birth order and asthma or wheeze changed over time in a study that included, with few exceptions, children from the same geographical areas and in which the questions on respiratory illness were the same.

\section{Methods}

In the NSHG areas were selected in England and Scotland by stratified random sampling of employment exchange areas using data on unemployment, early school leavers, and on children receiving free school meals. ${ }^{18}$ More areas were selected from poorer than wealthier strata. Primary schools were selected in each area and all children in the school were included in the sample, with the exception of two very large schools in which half the children were

Table 1 Prevalence of the two outcome measures, wheeze or asthma attacks, and bronchitis attacks, in the 1977, 1986, and 1994 surveys

\begin{tabular}{llll}
\hline Survey & Sex & $\begin{array}{l}\text { Wheeze or asthma attacks } \\
n / N(\%)\end{array}$ & $\begin{array}{l}\text { Bronchitis attacks } \\
n / N(\%)\end{array}$ \\
\hline 1977 & Boys & $538 / 4343(12.4)$ & $181 / 4343(4.2)$ \\
& Girls & $321 / 4191(7.7)$ & $111 / 4191(2.6)$ \\
1986 & Boys & $670 / 4893(13.7)$ & $120 / 4893(2.5)$ \\
& Girls & $415 / 4520(9.2)$ & $90 / 4430(2.0)$ \\
1994 & Boys & $767 / 4564(16.3)$ & $68 / 4564(1.5)$ \\
& Girls & $520 / 4448(11.7)$ & $39 / 4448(0.9)$ \\
\hline
\end{tabular}


Table 2 Prevalence of asthma attacks or wheeze according to number of older and younger siblings (1977, 1986, and 1994 surveys)

\begin{tabular}{|c|c|c|c|c|c|c|}
\hline & \multicolumn{6}{|c|}{ Number of older siblings } \\
\hline & 0 & 1 & 2 & 3 or more & Unknown & Total \\
\hline Number of younger siblings & $\mathrm{n} / \mathrm{N}(\%)$ & $\mathrm{n} / \mathrm{N}(\%)$ & $\mathrm{n} / \mathrm{N}(\%)$ & $\mathrm{n} / \mathrm{N}(\%)$ & $\mathrm{n} / \mathrm{N}(\%)$ & $\mathrm{n} / \mathrm{N}(\%)$ \\
\hline 0 & $304 / 2204(13.8)$ & $745 / 6065(12.3)$ & $297 / 2581(11.5)$ & $181 / 1441(12.6)$ & $55 / 467(11.8)$ & $1582 / 12758(12.5)$ \\
\hline 1 & $715 / 6111(11.7)$ & $298 / 2474(12.0)$ & $93 / 757(12.3)$ & $52 / 414(12.6)$ & $55 / 375(14.7)$ & $1213 / 10131(12.0)$ \\
\hline 2 & $199 / 1854(10.7)$ & $51 / 580(8.8)$ & $19 / 199(9.5)$ & $14 / 117(12.0)$ & $12 / 108(11.1)$ & $295 / 2858(10.3)$ \\
\hline 3 or more & $48 / 445(10.8)$ & $17 / 162(10.5)$ & $7 / 72(9.7)$ & $4 / 35(11.4)$ & $6 / 44(13.6)$ & $82 / 758(10.8)$ \\
\hline Unknown & - & $9 / 50(18.0)$ & $6 / 102(17.2)$ & $26 / 151(17.2)$ & $18 / 150(12.0)$ & $59 / 453(13.0)$ \\
\hline Total & $1266 / 10614(11.9)$ & $1120 / 9331(12.0)$ & $422 / 3711(11.4)$ & $277 / 2158(12.8)$ & $146 / 1144(12.8)$ & \\
\hline
\end{tabular}

Table 3 Asthma attacks or wheeze by family size, and child's sex and age (adjusted for all other factors in the table, father's social class, year or survey, and area of survey)

\begin{tabular}{lllll}
\hline & Number & $\%$ & OR $(95 \%$ CI $)$ & p Value (all OR $=1.00)$ \\
\hline Total number of siblings & & & & $\mathrm{p}=0.22$ \\
$\quad 0$ & $322 / 2320$ & 13.9 & 1.00 & \\
1 & $1495 / 12514$ & 12.0 & $0.88(0.77,1.00)$ & \\
2 & $823 / 7063$ & 11.7 & $0.86(0.75,0.99)$ & \\
3 or more & $493 / 4355$ & 11.3 & $0.84(0.72,0.98)$ & \\
$\quad$ Unknown & $98 / 707$ & 13.9 & $0.94(0.73,1.20)$ & \\
Sex & & & & $\mathrm{p}<0.001$ \\
$\quad$ Boys & $1975 / 13800$ & 14.3 & 1.00 & \\
$\quad$ Girls & $1256 / 13159$ & 9.5 & $0.63(0.58,0.68)$ & \\
Age (for one year increase) & NA & NA & $0.93(0.91,0.95)$ & $\mathrm{p}<0.001$ \\
\hline
\end{tabular}

invited to participate. In each area we tried to recruit one school only, but if the school had less than 200 children an additional school was recruited. In some rural areas several small schools were invited to participate. The 1977, $1985 / 86$, and 1993/4 surveys were selected for the current analysis to provide three surveys in which parents of all the children in the study answered the same questions on respiratory illness and separated by a maximum period of time. In the 1985/86 and 1993/94 surveys all English children and half of the Scottish children were surveyed in 1986 or 1994. As most children were surveyed in 1986 or 1994 these years will be used for identifying the surveys. The 1977 survey was used instead of earlier surveys because only parents of children previously in the study were asked the identical questions on child's respiratory illness before 1977.

Information on respiratory illness in the children was obtained from a self administered questionnaire usually completed by the mother. For the current analysis the following information was used: whether the child had experienced asthma attacks or bronchitis attacks in the last 12 months, in separate questions, and whether his or her chest ever sounded wheezy or whistling. In this study asthma attacks or wheeze ever was used as the definition of asthma. As the reported preva- lence of bronchitis attacks has decreased over time further analysis was carried out adding bronchitis attacks to the definition of asthma.

The explanatory variables used in the analysis were child's age and sex, number of siblings, number of younger children, number of older children, father's social class based on occupation, and area in the study to adjust for the area characteristics associated with asthma. Father's social class was divided into four groups: nonmanual, skilled manual, semi or unskilled manual, and unknown social class. The unknown social class group included children whose parents did not answer the question or those in one parent families in which the mother was the head of the family. The questions did not change over the period of observation except that for participants in 1977 we asked about the number of younger children, older children, and total number of children in the family while in the other surveys we asked only about number of older children and total number of children in the family. Only children with no information on the respiratory illness questions described above, unknown sex or age were omitted in the analysis. A "not known" category was included for the other independent variables in the analysis.

In the main analysis logistic regressions were carried out separately for total number of siblings, number of older, and number of younger siblings for each survey and in an analysis including data from all three surveys (1977, 1986, and 1994). The main purpose of the combined analysis was to assess whether there was a statistically significant interaction between year of survey and number of siblings on asthma. The dependent variable was dichotomised into two groups, those children with asthma attacks or wheeze (asthma group) and the rest. The analysis was repeated dichotomising the dependent variable into the groups

Table 4 Prevalence and odds ratios of asthma attacks or wheeze by total number of siblings and father's social class in the 1977, 1986, and 1994 surveys (adjusted for each factor in the table, child's age and sex, and geographical area)

\begin{tabular}{|c|c|c|c|c|c|c|}
\hline & \multicolumn{2}{|l|}{1977 survey } & \multicolumn{2}{|l|}{1986 survey } & \multicolumn{2}{|l|}{1994 survey } \\
\hline & $\%(n)$ & $O R(95 \% C I)$ & $\%(n)$ & $O R(95 \% C I)$ & $\%(n)$ & $O R(95 \% C I)$ \\
\hline Total siblings & & $\mathrm{p}=0.70$ & & $\mathrm{p}=0.20$ & & $\mathrm{p}=0.15$ \\
\hline 0 & $10.4(704)$ & 1.00 & $13.7(842)$ & 1.00 & $17.3(774)$ & 1.00 \\
\hline 1 & $10.0(3867)$ & $0.99(0.76,1.30)$ & $11.6(4643)$ & $0.87(0.70,1.08)$ & $14.3(4004)$ & $0.83(0.67,1.02)$ \\
\hline 2 & $10.3(2220)$ & $1.07(0.81,1.42)$ & $10.6(2473)$ & $0.81(0.63,1.02)$ & $14.0(2370)$ & $0.80(0.64,1.00)$ \\
\hline 3 or more & $9.5(1589)$ & $0.99(0.73,1.34)$ & $11.0(1257)$ & $0.84(0.66,1.13)$ & $13.5(1509)$ & $0.77(0.61,0.98)$ \\
\hline Unknown & $13.0(154)$ & $1.37(0.80,2.34)$ & $16.7(198)$ & $1.21(0.80,1.89)$ & $12.7(355)$ & $0.67(0.47,0.97)$ \\
\hline Father's occupation & & $\mathrm{p}=0.0050$ & & $\mathrm{p}=0.0002$ & & $\mathrm{p}=0.0031$ \\
\hline Non-manual & $10.7(2140)$ & 1.00 & $10.7(3250)$ & 1.00 & $12.5(2710)$ & 1.00 \\
\hline Skilled manual & $8.5(2930)$ & $0.79(0.65,0.96)$ & $11.0(3263)$ & $1.09(0.93,1.29)$ & $13.8(2756)$ & $1.13(0.96,1.32)$ \\
\hline Semi and unskilled manual & $11.8(1265)$ & $1.15(0.91,1.44)$ & $11.4(1338)$ & $1.11(0.94,1.44)$ & $16.4(1254)$ & $1.38(1.12,1.66)$ \\
\hline Unknown & $10.5(2196)$ & $0.99(0.81,1.21)$ & $14.7(1562)$ & $1.52(1.26,1.85)$ & $15.9(2292)$ & $1.30(1.10,1.54)$ \\
\hline
\end{tabular}


either with asthma attacks, bronchitis attacks or wheeze, or none of these.

\section{Results}

Altogether 26959 (90\%) children were included in the analysis out of an eligible sample of 29946 . Of these 8534 participated in 1977, 9413 in 1986, and 9012 in 1994.

Wheeze or asthma attacks was more prevalent in boys than girls and its prevalence increased over time (table 1). Bronchitis attacks was also more prevalent in boys than girls, but its prevalence has decreased over time in both sexes. There was an inconsistent small decrease in the prevalence of children with asthma attacks or wheeze by number of younger siblings (table 2). There was no indication that asthma was related to number of older siblings. The overall association between total number of siblings and the prevalence of asthma in the total sample was not statistically significant $(\mathrm{p}=0.22)$ (table 3$)$. The trend adjusted for sex, age, year of survey, area, and social class, was only marginally significant $(\mathrm{p}=0.052)$, and odds ratio $(\mathrm{OR})$ per sib $0.96(95 \%$ CI 0.92 to 1.00$)$. However, this model did not fit as well as the contrast of asthma with at least one sibling in comparison with asthma in families with an only child (adjusted OR 0.87, 95\% CI 0.76 to 0.98). Birth order was unrelated to asthma in the total sample and in each of the surveys (not shown).

Table 3 shows the prevalence and ORs for asthma by number of siblings, child's age and sex adjusted for area, year of survey, and father's social class. The interaction of year of survey and number of siblings on asthma was not statistically significant $(p=0.36)$. Child's age and sex were highly significantly associated with asthma $(p<0.001)$. The odds for asthma were higher in boys, for younger age groups, and in more recent than older surveys (1986 greater than 1977 and 1994 greater than 1986). The interaction of father's social class and year of survey was significantly associated with asthma $(p=0.004)$. There was an overall
KEY POINTS

- Recent research, but not that over 15 years ago, suggested a negative association between number of siblings and clinical atopy.

- Using the same methodology we assessed the association of asthma with family size and social class over 18 years.

- Asthma and family size were not associated in the 1977 and 1986 surveys, but they were marginally so in 1994 .

- Asthma has become more prevalent in children from lower social classes.

- Changes in risk factors of asthma over time should be taken into account in the search for new explanations of aetiology.

increase of asthma, but with a greater increase in the semi and unskilled social classes in the 1994 survey to a prevalence of $16.4 \%$ in comparison with $12.5 \%$ in non-manual social classes (table 4). There was also an increase in the prevalence of asthma in the unknown social class in the 1986 and 1994 surveys in comparison with the 1977 survey. Asthma was more prevalent in the skilled manual class in the 1986 and 1994 surveys $(12.2 \%)$ than in the 1977 survey (8.5\%).

Although the overall interaction of year of survey and number of siblings was not significant $(p=0.36)$ the ORs of asthma by family size showed some change over the period of observation (table 3). The association between these variables was not significant in any of the three surveys, but some categories, especially in the 1994 survey, were significant in comparison with the reference group. The adjusted OR for asthma in children with any siblings compared with none in 1986 and 1994 decreased by a factor of 0.82 (95\% CI 0.61 to 1.11$)$ over that in 1977. For number of siblings the odds of asthma was the highest in families with one child in 1986 and 1994 but not in 1977. Age and sex are

Table 5 Father's social class distribution by family size in the 1977, 1986, and 1994 surveys

\begin{tabular}{|c|c|c|c|c|}
\hline & \multicolumn{4}{|l|}{ Father's social class } \\
\hline & Non-manual $n(\%)$ & Skilled manual $n$ (\%) & Semi and unskilled $n(\%)$ & Unknown n (\%) \\
\hline \multicolumn{5}{|l|}{1977 survey } \\
\hline \multicolumn{5}{|l|}{ No of siblings } \\
\hline 0 & $157(7.3)$ & $210(7.2)$ & $101(8.0)$ & $235(10.7)$ \\
\hline 1 & $1103(51.5)$ & $1353(46.2)$ & $510(40.3)$ & $900(41.0)$ \\
\hline 2 & $591(27.6)$ & $744(25.4)$ & $333(26.3)$ & $552(25.1)$ \\
\hline 3 or more & $262(12.2)$ & $577(19.7)$ & $300(23.7)$ & $449(20.5)$ \\
\hline Unknown & $27(1.3)$ & $46(1.6)$ & $21(1.7)$ & $60(2.7)$ \\
\hline Total & 2140 & 2930 & 1265 & 2196 \\
\hline \multicolumn{5}{|l|}{1986 survey } \\
\hline \multicolumn{5}{|l|}{ No of siblings } \\
\hline 0 & $211(6.5)$ & $264(8.1)$ & $110(8.2)$ & $257(16.5)$ \\
\hline 1 & $1742(53.6)$ & $1673(51.3)$ & $590(44.1)$ & $638(40.9)$ \\
\hline 2 & $898(27.6)$ & $868(26.6)$ & $336(25.1)$ & $371(23.8)$ \\
\hline 3 or more & $357(11.0)$ & $404(12.4)$ & $262(19.6)$ & $234(15.0)$ \\
\hline Unknown & $42(1.3)$ & $54(1.7)$ & $40(3.0)$ & $62(4.0)$ \\
\hline Total & 3250 & 3263 & 1338 & 1562 \\
\hline \multicolumn{5}{|l|}{1994 survey } \\
\hline \multicolumn{5}{|l|}{ No of siblings } \\
\hline 0 & $162(6.0)$ & $201(7.3)$ & $83(6.6)$ & $328(14.3)$ \\
\hline 1 & $1389(51.3)$ & $1268(46.0)$ & $539(43.0)$ & $808(35.3)$ \\
\hline 2 & $710(26.2)$ & $758(27.5)$ & $331(26.4)$ & $571(24.9)$ \\
\hline 3 or more & $373(13.8)$ & $443(16.1)$ & $243(19.4)$ & $450(19.6)$ \\
\hline Unknown & $76(2.8)$ & $86(3.1)$ & $58(4.6)$ & $135(5.9)$ \\
\hline Total & 2710 & 2756 & 1254 & 2292 \\
\hline
\end{tabular}


not shown because they did not change their level of association over time.

In Table 5 the distribution of fathers social class is shown by sibship size in the three surveys as these are the two variables of interest in the analysis shown above. Children with one other sibling in the family were more frequent in families in which the father had a nonmanual occupation and was less frequent in families in which the father had a semi or unskilled occupation while the frequency of those with a father with a skilled manual occupation was intermediate. The opposite trend was observed in families in which the participating child had three or more siblings. These distributions did not change over time.

The analyses were repeated with a dependent variable in which children with bronchitis attacks were added to the group with asthma, but the analyses did not identify any difference in relation to the analysis shown in table 4 .

\section{Discussion}

This study is the first to assess the evolution of the relation between asthma prevalence and family size over time (17 years). An overall association between family size and asthma has not been confirmed in the total sample of the three surveys, nor were the variables significantly associated at the conventional statistical level $(p<0.05)$ in any of the three surveys individually. However, the prevalences and ORs showed that an only child had a higher prevalence of asthma than children with siblings in the 1993/94 surveys and to a lesser extent in the $1985 / 86$, but this characteristic was not apparent in the 1977 survey, although the interaction was not statistically significant. The confidence intervals for the OR for the interaction between the latter two surveys and the first with this contrast were wide, but taken in conjunction with other studies this may provide some support to a change in the relation over time. The association between sibship size and asthma differs from the results reported for the 1990-1991 survey, which showed a highly significant decreasing prevalence of asthma with increasing number of siblings in the family. ${ }^{11}$ The previous evidence in the literature shows that atopic conditions were negatively associated with number of siblings and none showed the association to be related to a family size threshold. ${ }^{1-11}$ The association between asthma and number of siblings was not changed by the inclusion of children with bronchitis attacks. Thus diagnostic labelling did not affect the association between asthma and number of siblings. Birth order was not associated with asthma in this analysis, but it was associated in our previous analysis, although the strength was less than for sibship size. ${ }^{11}$

The hypothesis that a decrease in repeated viral infection is an explanation for the negative relation between birth order and an atopic condition has been suggested mainly for hay fever, sensitisation, and eczema. ${ }^{12}$ No similar association was reported for asthma using the same data as for eczema and hay fever (the 1958 and 1970 birth cohort studies). ${ }^{17}{ }^{19}$ Although the authors restricted their analysis to birth order and did not include family size in the analysis, a previous account of the 1958 cohort reported no association between family size and asthma in 7 and 11 year olds. ${ }^{16}$ The association between family size and asthma in recent publications comes from studies in New Zealand, ${ }^{9}$ the US, ${ }^{10}$ and Britain, ${ }^{7}{ }^{11}$ but this association was not detected in a Finnish study based on twins. ${ }^{20}$ As the studies recently reporting an association included children ${ }^{9-11}$ and young adults ${ }^{7}$ it is more plausible to suggest that, if the association is confirmed, the changes in the relation between sibship size and asthma are related to a period effect rather than a cohort effect. This interpretation of the evidence would make less likely, as an explanation of the association between asthma and number of siblings, the hypothesis that repeated infection in early life would protect the person from asthma later on. More probable candidates to explain the association are changes in the perception of wheeze in the population or the universal exposure to a new environmental agent. There are many factors that may have been widely introduced to the population, for example a decrease in physical activity, an increase in obesity, changes in food intake or air pollution. It is unclear how any of these factors would have affected susceptibility to asthma by family size or birth order, although some evidence exists that obesity is related to asthma. ${ }^{21}$ There is still the possibility that the infection theory has a role in relation to the other atopic conditions, but Strachan states that epidemiological evidence relating early infection to subsequent development of allergy is currently far from convincing. ${ }^{12}$

The association of asthma with sex ${ }^{10} 11141720$ and age $\mathrm{e}^{101122}$ is consistent with other studies in children. Our finding that the association between asthma and social class has been changing over time has not been reported before. In the most recent survey in our analysis the prevalence of asthma is higher in lower social classes. Analyses based on the 1958 birth cohort do not show an association between asthma and social class, ${ }^{1622}$ but in the 1970 birth cohort asthma prevalence was higher in the semi and unskilled manual classes and the managerial social class. ${ }^{17}$ Wheeze has been found more prevalent in children whose fathers are in unskilled social class in two large studies. ${ }^{2324}$ Whincup and colleagues showed the association between wheeze most days and social class to be similar in 1966 and $1990 .^{23}$ The differences between the two studies may be because of our use of a composite definition of asthma that included several symptoms while Whincup and colleagues based their analysis on wheeze most days only. In the US it has been reported that asthma is more prevalent in children living in extreme poverty, ${ }^{25}$ but this finding has not been confirmed by other researchers. ${ }^{10}$ There are several studies that indicate that extreme poverty or lower social class are risk factors for asthma. In these studies it is important to distinguish between surveys in the community and hospital admissions. There is little doubt that poverty is positively associated with 
hospital admissions for asthma. ${ }^{25}$ However, the reports based on community studies are inconsistent. In this analysis we did not include parents' smoking as an independent variable. Information on parents' smoking was not requested in 1986 and the question wording was different in 1977 and 1994.

This paper provides lukeworm support to the hypothesis that asthma is currently associated negatively with sibship size. Based on this analysis the magnitude of the association, if existing at all, is small. Using similar methodology over the study period the analysis suggests, albeit not unambiguously, that the association between asthma and family size may have arisen only recently. Based on the results from this study the explanation of the association of asthma and sibling number as caused by repeated viral infection in childhood is not compelling. The search for alternative explanations should continue.

The authors thank colleagues in the team and all parents, children, and helpers in the study areas.

Funding: the study was funded by the Department of Health and Scottish and Health Department.

Conflicts of interest: none.

1 Golding J, Peters T. Eczema and hay fever. In: Butler N, Golding J, eds. From birth to five. A study of the health and behaviour of Britain's five year-olds. Oxford: Pergamon, behaviour of

2 Strachan DP. Hay fever, hygiene, and household size. $B M \mathcal{F}$ 1989;299:1259-60.

3 Strachan DP, Taylor EM, Carpenter RG. Family structure, neonatal infection, and hay fever in adolescence. Arch Dis Child 1996;74:422-6.

4 von Mutius E, Martinez FD, Fritzsch C, et al. Skin test reactivity and number of siblings. BMF 1994;308:692-5.

5 Strachan DP, Harkins LS, Johnston IDA, et al. Childhood antecendents of allergic sensitization in young British adults. F Allergy Clin Immunol 1997;99:6-12.

6 Brabeck L, Breborowics A, Julge K, et al. Risk factors for respiratory symptoms and atopic sensitisation in the Baltic area. Arch Dis Child 1995;72:487-93.
7 Jarvis D, Chinn S, Luczynska C, et al. The association of family size with atopy and atopic disease. Clin Exp Allergy family size with

8 Matricardi PM, Rosmini F, Ferrigno L, et al. Cross sectional retrospective study of prevalence of atopy among Italian students with antibodies against hepatitis A virus. BMF 1997;314:999-1003.

9 Crane J, Pearce N, Shaw R, et al. Asthma and having children. BMF 1994;309:272.

10 Stoddard JJ, Miller T. Impact of parental smoking on the prevalence of whering respiratory illness in children. $A m \mathcal{F}$ Epidemiol 1995;141:96-102.

11 Rona RJ, Duran-Tauleria E, Chinn S. Family size, atopic disorders in parents, asthma in children, and ethnicity. $\mathcal{F}$ Allergy Clin Immunol 1997;99:454-60.

12 Strachan DP. Allergy and family size: a riddle worth solving. Clin Exp Allergy 1997;27:235-7.

13 Martinez FD. Role of viral infections in the inception of asthma and allergies during childhood. Thorax 1994;49: 1189-91.

14 Davis JB, Bulpitt CJ. Atopy and wheeze in children according to parental atopy and family size. Thorax $1981 ; 36: 185-$ 9.

15 Hamman RF, Halil T, Holland WW. Asthma in schoolchildren. Demographic associations and peak expiratory flow rates compared with children with bronchitis. Br 7 Prev Soc Med 1975;29:228-38.

16 Peckham C, Butler N. A national study of asthma in childhood. F Epidemiol Community Health 1978;32:79-85.

17 Lewis S, Butland B, Strachan D, et al. Study of the aetiology of wheezing illness at age 16 in two national British birth of wheezing illness at age 16 in

18 Rona RJ, Altman DG. National Study of Health and Growth: Standards of attained height, weight and triceps kinfold in English children 5 to 11 years old. Ann Hum Biol 1977;4:501-23.

19 Strachan DP, Butland BK, Anderson HR. Incidence and prognosis of asthma and wheezing illness from early childhood to age 33 in a national British cohort. BMF 1996;312: $1195-9$

20 Räsänen M, Laitinen T, Kaprio J, et al. Hay fever, asthma and number of older siblings - a twin study. Clin Exp Allergy 1997;27:515-18

21 Somerville S, Rona R, Chinn S. Obesity and respiratory symptoms in primary school. Arch Dis Child 1984;59:9404.

22 Strahan DP, Anderson HR, Limb ES, et al. A national survey of ashma prevalence and treatment in Great Britain. Arch Dis Child 1994;70:174-8.

23 Whincup PH, Cook DG, Strachan DP, et al. Time trends in respiratory symptoms in childhood over a 24 year period. Arch Dis Child 1993;68:729-34.

24 Weitzman M, Gortmaker S, Sobol A. Racial, social, and environmental risks for childhood asthma. Am $\mathcal{f}$ Dis Child 1990;144:1189-94.

25 Wissour LS, Gittelsohn AM, Szklo M, et al. Poverty, race, and hospitalization for childhood asthma. Am f Public Health 1988;78:777-82. 